\title{
UTJECAJ METODA ISPITIVANJA NA ENERGIJU KLIJANJA I KLIJAVOST SJEMENA ENDIVIJE (Cichorium endivia L.)
}

\author{
INFLUENCE OF TESTING METHODS ON GERMINATION \\ ENERGY AND SEED GERMINATION OF ENDIVE
}

(Cichorium endivia L.)

\section{Iva Rojnica, Dijana Horvat, Marina Palfi, Andrea Pečarić}

\section{SAŽETAK}

Endivija (Cichorium endivia L.) je povrtna vrsta čije se potrebite količine sjemena u Hrvatskoj svake godine povećavaju zbog sve većeg broja vrtlara hobista. Posljednjih nekoliko godina u laboratorijima za kontrolu kvalitete poljoprivrednog sjemena zapaženo je da sjeme endivije neovisno o sorti ima nisku energiju klijanja i klijavost.

Cilj ovog istraživanja je ispitati navedene pokazatelje kvalitete sjemena endivije različitim metodama koje se koriste kod ispitivanja klijavosti povrtnih kultura. Korištena je metoda na filtar- papiru s četiri tretmana 1) vlaženje podloge destiliranom vodom, 2) vlaženje podloge $0,2 \%$-tnom otopinom $\mathrm{KNO}_{3}$, 3) prethodno hlađenje + vlaženje podloge destiliranom vodom, 4) prethodno hlađenje + vlaženje podloge $0,2 \%$-tnom otopinom $\mathrm{KNO}_{3}$. Ispitivanje je provedeno u laboratoriju za kontrolu kvalitete poljoprivrednog reprodukcijskog materijala Visokog gospodarskoga učilišta u Križevcima. Nakon provedenog ispitivanja rezultati pokazuju da su najvišu energiju klijanja i klijavost sjemena imali uzorci kod kojih je korišten predtretman prethodno hlađenje i destilirana voda, a značajno nižu energiju i klijavost sjemena imali su uzorci kod kojih je korištena metoda vlaženja podloge s $0,2 \%$-tnom otopinom $\mathrm{KNO}_{3}$.

Ključne riječi: metode ispitivanja, energija klijanja, klijavost, endivija

\section{ABSTRACT}

Endive (Cichorium endivia L.) is a vegetable species whose needs for seed quantity increase each year due to the growing number of hobby gardeners. Furthermore, in the last few years, it has been observed in control laboratories for seed quality that endive, regardless of its variety, has low germination energy and seed germination. 
Iva Rojnica i sur.: Utjecaj metoda ispitivanja na energiju klijanja i klijavost sjemena endivije (Cichorium endivia L.)

The aim of this study is to examine the germination energy and seed germination of endive applying various methods used in the examination of vegetable species. The study was conducted in the laboratory for quality control of agricultural reproductive material at Križevci College of Agriculture.

Energy and seed germination were tested by a four-treatment paper filter method. The first two treatments were comprised of wetting the substrate with distilled water and $0,2 \% \mathrm{KNO}_{3}$, while the other two treatments were a combination of both, along with a prior pre-cooling treatment. The highest seed germination and germination energy was evidenced in samples using pretreatment pre-cooling and distilled water, while samples that were treated with a $0,2 \% \mathrm{KNO}_{3}$ wetting method, as prescribed by the Ordinance of sampling methods and seed quality testing (OG 99/08) showed significantly lower energy and seed germination. Based on the results of the research, it was found that the best method for testing germination energy and seed germination was the paper filter method with wetting of the substrate with distilled water and applying precooling as a pre-treatment.

Key words: testing methods, germination energy, germination, endive

\section{UVOD}

Endivija (Cichorium endivia L.) je povrtna kultura koja se najviše koristi svježa kao salata, a može biti i kuhana kao prilog jelu. Poznata je po zdravstveno korisnim sastojcima, a zbog male energetske vrijednosti često se koristi kao dijetalna namirnica. Uzgoj endivije najviše je zastupljen u južnoj Europi, a kod nas je najveća proizvodnja u mediteranskom području (Lešić i sur., 2016.). U Hrvatskoj nema proizvodnje sjemena endivije, pa je ponuda bazirana na uvozu. Sjemenu povrća koje se uvozi i prepakirava u Hrvatskoj (Pravilnik o stavljanju na tržište sjemena povrća NN 129/07, 78/10, 43/13, $29 / 14,36 / 15,84 / 16)$ potrebno je prije stavljanja na tržište ispitati klijavost. Za svaku biljnu vrstu propisana je jedna ili više metoda ispitivanja energije klijanja i klijavosti sjemena (Pravilnik o metodama uzorkovanja i ispitivanja kvalitete sjemena NN 99/08). Kod biljnih vrsta čije sjeme pokazuje svojstvo dormantnosti propisane su metode koje omogućuju prekidanje dormantnosti. Dormantno sjeme ne klije u uvjetima koji su povoljni za klijanje (Baskin i Baskin, 2004.). Dormantnost predstavlja prilagodbu biljaka koja onemogućuje klijanje sjemena nakon sazrijevanja, što je u mnogim klimatskim uvjetima poželjno svojstvo (Bewley, 1997.) kako ne bi došlo do priježetvenog klijanja i velikih gubitaka (Gubler i sur., 2005.). Prekidanjem stanja dormantnosti 
Iva Rojnica i sur.: Utjecaj metoda ispitivanja na energiju klijanja i klijavost sjemena endivije (Cichorium endivia L.)

sjemena i utjecajima određenih čimbenika na njegovu klijavost bavili su se mnogi istraživači. Čmelik i Perica (2007.) također smatraju da je dormantnost sjemena njegova prirodna osobina koja velikom broju biljnih vrsta pruža mogućnost mirovanja u nepovoljnim uvjetima, sve dok ti uvjeti ne postanu povoljni za klijanje sjemena. Kako bi dormantno sjeme moglo proklijati, potrebno je određenim metodama prekinuti stanje dormancije ili mirovanja, u suprotnom dormantno sjeme neće proklijati niti u odgovarajućim uvjetima potrebnim za normalno klijanje (temperatura, vlaga, kisik i ostali faktori), isto navode i brojni drugi autori (Hilhorst, 1995., Li i Foley, 1997., Baskin i Baskin, 2004.). Naglašavaju važnost dormantnosti za mnoge biljke, jer kad nje ne bi bilo sjeme mnogih kultura ne bi moglo preživjeti hladne zimske uvjete. Dormantnost se može skratiti ili prekinuti, a klijavost povećati sljedećim postupcima: naklijavanjem u mraku (Gubler i sur., 2008.), tretiranjem sjemena svjetlom različitog spektra (Burger, 1965.; Pons, 1991.; Baskin i Baskin, 1998.), tretiranjem sjemena kemikalijama i hormonima kao što je vodikov peroksid, natrijev i kalijev hidroksid, $\mathrm{GA}_{3}$ (Ogawa i Iwabuchi, 2001.; Hou i Simpson, 1994.; Vieira i sur., 2002.), tretiranjem sjemena visokim i niskim temperaturama (Reuss i sur., 2004.; Bethke i sur., 2004.; Baskin i Baskin, 1998.), mehaničkom skarifikacijom te suhim skladištenjem sjemena (Baskin i Baskin, 1998.; Lenoir i sur., 1986.). Postavljene su brojne hipoteze o prirodi dormantnosti, ali mehanizmi iniciranja, održavanja i prekida dormancije još uvijek su nedostatno razjašnjeni (Dennis, 1994.; Bewley, 1997.). Posljednjih nekoliko godina u laboratorijima za kontrolu kvalitete poljoprivrednog sjemena zapaženo je da sjeme endivije neovisno o sorti ima nisku energiju klijanja i klijavost sjemena. Kod sjemena endivije pravilnikom (Pravilnik o metodama uzorkovanja i ispitivanja kvalitete sjemena NN 99/08) je propisana metoda ispitivanja klijavosti sjemena na filtar papiru uz vlaženje podloge $0,2 \%$-tnom otopinom $\mathrm{KNO}_{3}$ kao predtretmana u svrhu prekidanja dormantnosti. Cilj provedenog istraživanja bio je utvrditi razlike u energiji klijanja i klijavosti sjemena korištenjem različitih metoda ispitivanja.

\section{METODE I MATERIJALI ISTRAŽIVANJA}

Ispitivanje energije klijanja i klijavosti sjemena provedeno je u Laboratoriju za ispitivanje kvalitete poljoprivrednog reprodukcijskog materijala na Visokom gospodarskom učilištu u Križevcima. Istraživanje je provedeno na pet uzoraka sjemena endivije (Eskariol žuta, Dječja glava, Pancalieri, Kopica i Mix različitih sorata). Korištena je metoda na filtar papiru sa četiri različita tretmana (Tablica 1.). 
Iva Rojnica i sur.: Utjecaj metoda ispitivanja na energiju klijanja i klijavost sjemena endivije (Cichorium endivia L.)

Tablica 1. Tretmani u ispitivanju energije i klijavosti sjemena

Table 1 Treatments in energy testing and seed germination

\begin{tabular}{|l|r|}
\hline 1. & vlaženje podloge destiliranom vodom \\
\hline 2. & vlaženje podloge $0,2 \%$-tnom otopinom $\mathrm{KNO}_{3}$ \\
\hline 3. & vlaženje podloge destiliranom vodom + prethodno hlađenje $(\mathrm{PH})$ \\
\hline 4. & vlaženje podloge $0,2 \%$-tnom otopinom $\mathrm{KNO}_{3}+$ prethodno hlađenje $(\mathrm{PH})$ \\
\hline
\end{tabular}

Sjeme je pravilno raspoređeno na navlažen sloj filtar papira u Petrijeve zdjelice. Za svaki tretman postavljeno je 100 sjemenki u četiri ponavljanja kod svih pet uzoraka. Naklijavanje sjemena endivije provedeno je na temperaturi od $20^{\circ} \mathrm{C}$ u klijališnoj komori (Termomedicinski aparati Bodalec), pri svjetlosnom režimu $12 \mathrm{~h}$ dan/12 h noć. Kod predtretmana hlađenja, sjeme je na podlozi za naklijavanje stavljeno u hladnjak na temperaturu od $5^{\circ} \mathrm{C}$ pet dana, nakon čega je premješteno u klijališnu komoru na propisanu temperaturu. Peti dan nakon postavljanja sjemena na naklijavanje očitavala se energija klijanja, a nakon 14 dana klijavost sjemena, nenormalni klijanaci i neklijavo sjeme (Pravilnik o načinu uzorkovanja i ispitivanja kvalitete sjemena NN 99/08). Rezultati energije klijanja i klijavosti, izraženi su u postotcima, kao srednja vrijednost svih ponavljanja.

Statistička obrada eksperimentalnih podataka provedena je uporabom programa GraphPad Prism verzija 7. Dobivene vrijednosti svakog ispitivanog parametra statistički su obrađene dvosmjernom analizom varijance (ANOVA). Razlike su procijenjene pomoću Tukey testa višestruke usporedbe. Rezultati su smatrani statistički značajnim ako je p<0,05.

\section{REZULTATI I RASPRAVA}

Energija klijanja sjemena

Rezultati istraživanja pokazuju da je kod sjemena endivije Eskariol žute, Dječje glave i Mixa postignuta statistički značajno $(\mathrm{p}<0,05)$ viša energija klijanja primjenom predtretmana prethodnog hlađenja i vlaženja podloge destiliranom vodom (Tablica 2.) u odnosu na ostale tretmane. Kod sjemena endivije Kopice najviša energija klijanja postignuta je primjenom predtretmana prethodnog hlađenja i vlaženja podloge s $0,2 \%$-tnom otopinom $\mathrm{KNO}_{3}$ i prethodnog hlađenja $\mathrm{i}$ vlaženja podloge destiliranom, te postoji 
Iva Rojnica i sur.: Utjecaj metoda ispitivanja na energiju klijanja i klijavost sjemena endivije (Cichorium endivia L.)

statistički opravdana razlika $(\mathrm{p}<0,05) \mathrm{u}$ energiji klijanja u odnosu na ostale tretmane (Tablica 2.). Primjenom predtretmana prethodnog hlađenja i vlaženja podloge $\mathrm{s}$ 0,2\%-tnom otopinom $\mathrm{KNO}_{3}$ kod sjemena endivije Pancalieri postignuta je najviša energija klijanja koja je statistički značajno različita od ostalih korištenih tretmana. Tretman vlaženja podloge za naklijavanje $0,2 \%$ tnom otopinom $\mathrm{KNO}_{3}$ rezultirao je najnižom energijom klijanja kod četiriju uzoraka sjemena endivije (Dječja glava, Pancalieri, Kopica i Mix) te se statistički značajno razlikuje $(\mathrm{p}<0,05)$ u odnosu na postignutu energiju klijanja kod ostalih tretmana (Tablica 2.).

Tablica 2. Utjecaj metode za prekidanje mirovanja sjemena na energiju klijanja sjemena endivije

Table 2 Effect of the method of breaking seed dormancy on the energy of endive seeds germination

\begin{tabular}{|l|c|c|c|c|c|}
\hline & Eskariol žuta & Dječja glava & Pancalieri & Kopica & Mix \\
\hline $\begin{array}{l}\text { Destilirana voda / } \\
\text { Distilled water }\end{array}$ & $38,8 \pm 8,96 \mathrm{~d}$ & $41,8 \pm 13,48 \mathrm{~cd}$ & $82 \pm 6,78 \mathrm{ab}$ & $64,5 \pm 12,61 \mathrm{~b}$ & $60 \pm 10,86 \mathrm{bc}$ \\
\hline $\mathrm{KNO}_{3} / \mathrm{KNO}_{3}$ & $39,3 \pm 9,81 \mathrm{~cd}$ & $37 \pm 12,19 \mathrm{~d}$ & $68,8 \pm 4,35 \mathrm{~b}$ & $46,5 \pm 3,51 \mathrm{c}$ & $53,8 \pm 9,36 \mathrm{c}$ \\
\hline $\begin{array}{l}\text { Prethodno hlađenje } \\
+ \text { destilirana voda / } \\
\text { Previous cooling } \\
+ \text { distilled water }\end{array}$ & $80,5 \pm 12,90 \mathrm{a}$ & $90,3 \pm 3,30 \mathrm{a}$ & $78,8 \pm 4,03 \mathrm{ab}$ & $85 \pm 1,41 \mathrm{a}$ & $79,5 \pm 2,38 \mathrm{a}$ \\
\hline $\begin{array}{l}\text { Prethodno hlađenje } \\
+\mathrm{KNO}_{3} / \\
\begin{array}{l}\text { Previous cooling } \\
+\mathrm{KNO}_{3}\end{array}\end{array}$ & $50 \pm 16,08 \mathrm{bcd}$ & $58,5 \pm 16,38 \mathrm{~b}$ & $88,3 \pm 2,22 \mathrm{a}$ & $86 \pm 1,63 \mathrm{a}$ & $67,8 \pm 3,78 \mathrm{abc}$ \\
\hline
\end{tabular}

Rezultati su izraženi kao aritmetička sredina $\pm \mathrm{SD}(\mathrm{n}=4)$.

Results are expressed as mean $\pm S D(n=4)$.

$\mathrm{U}$ brojnim istraživanjima primjena otopine $\mathrm{KNO}_{3}$ u različitim postocima pokazala se učinkovitim sredstvom povećanja klijavosti sjemena (Shim i sur., 2008.; Fariman i sur., 2011.; Bian i sur., 2013.; Ruttanaruangboworn i sur., 2017.). Asci i sur. (2011.) su također utvrdili da je postotak klijanja crvene djeteline nakon skarifikacije $(54,2 \%)$ znatno viši nego u kontroli $(29,4 \%)$. Brzina klijanja je bila veća pri tretmanima prethodnog hlađenja (5 dana na $4{ }^{\circ} \mathrm{C}$ ), prethodnog grijanja ( 45 minuta u vodi na $60^{\circ} \mathrm{C}$ ), u tretmanu s ključalom vodom u odnosu na kontrolu i tretman $\mathrm{KNO}_{3}$. Sama energija klijanja nije istraživana, ali istraživanja pokazuju da prethodno hlađenje utječe na klijavost $\mathrm{i}$ brzinu klijanja kao i u ovom istraživanju. 
Iva Rojnica i sur.: Utjecaj metoda ispitivanja na energiju klijanja i klijavost sjemena endivije (Cichorium endivia L.)

Tablica 3. Utjecaj metode za prekidanje mirovanja sjemena na klijavost sjemena endivije

Table 3 Effect of the method of breaking seed dormancy on germination of endive seeds

\begin{tabular}{|l|c|c|c|c|c|}
\hline & Eskariol žuta & Dječja glava & Pancalieri & Kopica & Mix \\
\hline $\begin{array}{l}\text { Destilirana voda / } \\
\text { Distilled water }\end{array}$ & $80,8 \pm 6,70 \mathrm{a}$ & $80,8 \pm 2,63 \mathrm{abc}$ & $91 \pm 2,94 \mathrm{a}$ & $84,5 \pm 3,87 \mathrm{a}$ & $79,8 \pm 7,09 \mathrm{a}$ \\
\hline $\mathrm{KNO}_{3} / \mathrm{KNO}_{3}$ & $65,3 \pm 20,66 \mathrm{~b}$ & $78,3 \pm 6,29 \mathrm{c}$ & $86,8 \pm 3,20 \mathrm{a}$ & $76,8 \pm 6,13 \mathrm{a}$ & $78,5 \pm 5,75 \mathrm{a}$ \\
\hline $\begin{array}{l}\text { Prethodno hlađenje } \\
+ \text { destilirana voda / } \\
\text { Previous cooling } \\
+ \text { distilled water }\end{array}$ & $89,3 \pm 8,06 \mathrm{a}$ & $92,8 \pm 2,22 \mathrm{a}$ & $83,8 \pm 5,12 \mathrm{a}$ & $86,8 \pm 1,5 \mathrm{a}$ & $83,5 \pm 2,08 \mathrm{a}$ \\
\hline $\begin{array}{l}\text { Prethodno hlađenje } \\
+\mathrm{KNO}_{3} /\end{array}$ \\
$\begin{array}{l}\text { Previous cooling } \\
+\mathrm{KNO}_{3}\end{array}$
\end{tabular}

Rezultati su izraženi kao aritmetička sredina $\pm \mathrm{SD}(\mathrm{n}=4)$.

Results are expressed as mean $\pm S D(n=4)$

Klijavost sjemena

Prema rezultatima prikazanim u Tablici 3. klijavost sjemena endivije Eskariol žute najviša je kod primjene tretmana prethodnog hlađenja i vlaženja podloge destiliranom vodom, ali nema statistički značajne razlike $(\mathrm{p}<0,05) \mathrm{u}$ usporedbi s tretmanima prethodnog hlađenja i vlaženja podloge $0,2 \%$-tnom otopinom $\mathrm{KNO}_{3}$, te vlaženja podloge destiliranom vodom. Kod sjemena endivije Dječje glave primjenom prethodnog hlađenja i vlaženja podloge destiliranom vodom postignuta je najviša klijavost sjemena koja je statistički značajno različita od ostalih korištenih tretmana (Tablica 3.). Najniža klijavost sjemena endivije Eskariol žute i Dječje glave u odnosu na ostale tretmane postignuta je vlaženjem podloge $0,2 \%$-tnom otopinom $\mathrm{KNO}_{3}$. Kod ostalih ispitivanih sorti endivije (Pancalieri, Kopica, Mix) primjena različitih tretmana nije statistički opravdana, nema značajnih razlika u klijavosti sjemena primjenom različitih tretmana $\mathrm{u}$ procesu naklijavanja sjemena. Dobiveni rezultati ne slažu se s rezultatima Robertsa i Locketta (1978.) koji su otkrili da tretiranje podloge $\mathrm{s} \mathrm{KNO}_{3}$ u koncentraciji od $0,2 \%$ u tamnim uvjetima, povećava klijavost sjemena crne pomoćnice (Solanum nigrum L.) dok se u ovom istraživanju navedena metoda pokazala najlošija kod dva uzorka, a kod ostalih nije postignuta značajna razlika u klijavosti korištenjem ove metode. Tang i sur. (2008.) ispitivali su klijavost sjemena 
Iva Rojnica i sur.: Utjecaj metoda ispitivanja na energiju klijanja i klijavost sjemena endivije (Cichorium endivia L.)

bijele lobode (Chenopodium album L.) primjenom otopine $\mathrm{KNO}_{3}$ u različitim koncentracijama. Primijenili su pet koncentracija: $0,01 \%, 0,05 \%, 0,1 \%$, $0,25 \%$ i $0,5 \%$. Najveću ukupnu klijavost sjemenki lobode zabilježili su kada je sjeme tretirano 0,05\%-tnom otopinom $\mathrm{KNO}_{3}$. Đikić i sur. (2011.) istraživali su različite metode prekidanja dormantnosti divljeg sirka (Sorghum halepense L.). Ispitivali su utjecaj mehaničke skarifikacije sjemena, potapanja sjemena u vodu na 24 sata, zagrijavanje sjemena u vodi na $80{ }^{\circ} \mathrm{C}$, hladnu stratifikaciju sjemena na $4{ }^{\circ} \mathrm{C}$ tijekom 7 i 14 dana, te tretiranje $0,2 \%$-tnom otopinom $\mathrm{KNO}_{3}$. Stratifikacija sjemena, kemijski tretman 0,2\%-tnom otopinom $\mathrm{KNO}_{3}$ i mehanička skarifikacija nisu imali utjecaja na klijavost sjemena sirka. Lazić (2015.) navodi da primjena otopine $\mathrm{KNO}_{3}$, stratifikacija sjemena te potapanje sjemena u vodu prekida dormantnost sjemena oštrodlakavog šćira (Amaranthus retroflexus L.), a najviša klijavost utvrđena je u tretmanu $\mathrm{s}$ 2\%-tnom otopinom $\mathrm{KNO}_{3}$. Bewley i Black (1982.) navode da prisutnost otopine $\mathrm{KNO}_{3}$ podiže količinu kisika time što smanjuje dostupnost kisika ciklusu limunske kiseline $\mathrm{i}$ time poboljšava klijavost sjemena. S druge strane Mohammadi i sur. (2013.) navode da primjena otopine $\mathrm{KNO}_{3}$ uz sumpornu kiselinu ima manji učinak nego u tretmanu bez otopine $\mathrm{KNO}_{3}$. Na osnovi dosadašnjih istraživanja i provedenog istraživanja vidljivo je da primjena različitih predtretmana za prekidanje dormantnosti sjemena djeluje različito te ovisi i o vrsti sjemena.

\section{ZAKLJUČAK}

Energija i klijavost sjemena ispituju se u laboratorijima za kontrolu kvalitete poljoprivrednog sjemena metodom na filtar papiru uz vlaženje podloge 0,2\%-tnom $\mathrm{KNO}_{3}$ koja je propisana Pravilnikom o načinu uzorkovanja i ispitivanja kvalitete sjemena (NN 99/08). Rezultati istraživanja pokazuju da navedena metoda nije najprihvatljivija za ispitivanje energije i klijavosti sjemena endivije. Prema navedenim rezultatima kod ispitivanja energije klijanja sjemena najbolja se pokazala metoda vlaženje podloge destiliranom vodom i korištenjem prethodnog hlađenja kao predtretmana. Primjena različitih metoda ispitivanja klijavosti sjemena statistički je opravdana samo kod dva uzorka sjemena, ali je postotak klijavosti primjenom vlaženja podloge destiliranom vodom i korištenjem prethodnog hlađenja najviši kod četiriju od pet ispitivanih uzoraka. Rezultati dobiveni ovim istraživanjem pokazuju da je primjena metode prethodnog hlađenja uz vlaženje podloge destiliranom vodom najprihvatljivija za ispitivanje energije i klijavosti sjemena endivije. 
Iva Rojnica i sur.: Utjecaj metoda ispitivanja na energiju klijanja i klijavost sjemena endivije (Cichorium endivia L.)

\section{LITERATURA}

1. Asci O.O., Acar Z., Ayan I., Basaran U., Mut H. (2011.): Effect of pretreatments on seed germination rate of red clover (Trifolium pratense L.) populations. Afr J. Agric Res 6 (13): 3055-3060.

2. Baskin, C.C., Baskin, J.M. (1998.): Seeds - ecology, biogeography, and evolution of dormancy and germination. San Diego, CA, USA: Academic Press.

3. Baskin, J.M., Baskin, C.C. (2004.): A classification system for seed dormancy. Seed Science Research, 14: 1-16.

4. Bethke P.C., Gubler F., Jacobsen J.V., Jones R.L. (2004.): Dormancy of Arabidopsis seeds and barley grains can be broken by nitric oxide. Planta 219(5):847-855.

5. Bewley, J.D. (1997.): Seed dormancy and germination. The Plant Cell, 9: 1055-1066.

6. Bewley, B.D., Black, M. (1982.): Physiology and Biochemistry of Seeds in Relation to Germination. Volume 2: Viability, Dormancy and Environmental Control. Springer, Berlin.

7. Bian L., Yang L., Wang J., Shen H. (2013.). Effects of KNO3 pretreatment and temperature on seed germination of Sorbus pohuashanensis. J For Res 24(2): 309-316.

8. Burger W. C.(1965.): Effect of light on the germination of barley and its relation on dormancy. Journal of The Institute of Brewing. 71(3): 244-250.

9. Čmelik, Z., Perica, S. (2007.): Dormantnost sjemena voćaka. Sjemenarstvo, 24(1): 51-58.

10. Dennis, F., (1994.): Dormancy - what we know (and don't know). HortScience 29: $1249-1255$.

11. Đikić, M., Gadžo, D., Gavrić, T., Šapčanin, V., Podrug., A. (2011.): Dormancy and weed seed germination. Herbologia, 12(1): 149-155.

12. Fariman Z. K., Azizi M., Noori S. (2011.): Seed germination and dormancy breaking techniques for Echinacea purpurea L. J Biol Environ Sci 5(13): 7-10.

13. Gubler F., Hughes T., Waterhouse P., Jacobsen J. (2008.): Regulation of dormancy in barley by blue light and after - ripening: effects on abscisic acid and gibberellin metabolism. Plant physiology. 147:886-896.

14. Gubler F, Millar AA, Jacobsen JV (2005.): Dormancy release, ABA and preharvest sprouting. Curr Opin Plant Biol 8(2): 183-187. 
Iva Rojnica i sur.: Utjecaj metoda ispitivanja na energiju klijanja i klijavost sjemena endivije (Cichorium endivia L.)

15. Hillhorst, H.W.M. (1995.): A critical update on seed dormancy. I. Primary dormancy. Seed Science Research, 5: 61-73.

16. Hou J.Q., Simpson G.M. (1994.): Promoting germination of freshly harvested barley grain with alkaline solutions. Journal of the Institute of Brewing. 100(6): 421-425.

17. Lazić, A. (2015.): Dormantnost i klijavost sjemena oštrodlakavog šćira (Amaranthus retroflexus L.). Završni rad, Poljoprivredni fakultet u Osijeku, Osijek. pp. 26.

18. Lenoir C., Corbineau F., Côme D. (1986.): Barley (Hordeum vulgare) seed dormancy as related to glumella characteristics. Physiologia Plantarum 98(2): 301-307.

19. Lešić, R., Borošić, J., Buturac, I., Herak-Ćustić, M., Poljak, M., Romić, D., (2016.): Povrćarstvo. Zrinski, Čakovec

20. Li, B., Foley, M.E. (1997.): Genetic and molecular control of seed dormancy. Trends in Plant Science, 2: 384-389.

21. Mohammadi, G., Noroozi, N., Nosratti, I. (2013.): An evaluation of Johnson grass (Sorghum halepense L.) seed hardness removing methods. Journal of Agrobiology, 30(2): 83-88.

22. Ogawa K., Iwabuchi M. (2001.): A mechanism for promoting the germination of Zinnia Elegans seeds by hydrogen peroxide. Plant Cell Physiol. 42(3): 286-291.

23. Pons T. L. (1991.): Induction of dark dormancy in seeds: its importance for the seed banki in the soil. Functional Ecology.5: 669-675.

24. Pravilnik o metodama uzorkovanja i ispitivanja kvalitete sjemena (NN 99/08).

25. Pravilnik o stavljanju na tržište sjemena povrća (129/07, 78/10, 43/13, 29/14, $36 / 15,84 / 16)$.

26. Reuss R., Cassells J.A., Green J.R., Wills T., Nischwitz R. (2004.): Effect of chemical and physical processes on malting barley dormancy: The influence of physical and chemical processes on dormancy breakdown in malting barley. Canberra: CSIRO Entomology.

27. Roberts H.A., Lockett, P.M. (1978.): Seed dormancy and field emergence in Solanum nigrum L., Weed Research, 18: 231-241.

28. Ruttanaruangboworn A., Chanprasert W., Tobunluepop P., Onwimol D. (2017.). Effect of seed priming with different concentrations of potassium nitrate on the pattern of seed imbibition and germination of rice (Oryza sativa L.). J Integr Agric 16(3): 605-613. 
Iva Rojnica i sur.: Utjecaj metoda ispitivanja na energiju klijanja i klijavost sjemena endivije (Cichorium endivia L.)

29. Shim S. I., Moon J.-C., Jang C. S. , Raymer P., Kim W. (2008.). Effect of Potassium Nitrate Priming on Seed Germination of Seashore Paspalum. Hort Science 43(7).

30. Tang, D. S., Hamayun, M., Ko, Y.M., Zhang, Y.P., Kang, S.M., Lee, I.J. (2008.): Role of red light, temperature, stratification and nitrogen in breaking seed dormancy of Chenopodium album. J. Crop Sci. Biotech, 11 (3): 199-204.

31. Vieira A.R., Vieira M.G.G.C., Fraga A.C., Oliveira J.A., Santos C.D. (2002.): Action of gibberellic acid $\left(\mathrm{GA}_{3}\right)$ on dormancy and activity of a-amylase in rice seeds. Revista Brasileria de Sementes. 24(2): 43-48.

Adresa autora - Author's address:

Iva Rojnica, mag.ing.agr., dr. sc. Dijana Horvat,

Andrea Pečarić, bacc. ing. agr.

Visoko gospodarsko učilište u Križevcima

Milislava Demerca 1, Križevci, Hrvatska

dr. sc. Marina Palfi

Podravka d.d.

Ante Starčevića 32, Koprivnica, Hrvatska
Primljeno - Received:

22.10.2019. 